\title{
Validation of an Empirical Model for Innovation Diffusion in Australian Design Firms
}

\author{
Dr. Kriengsak Panuwatwanich \\ Lecturer, Griffith School of Engineering, Griffith University \\ Gold Coast Campus, Queensland 4222, Australia \\ k.panuwatwanich@griffith.edu.au
}

Dr. Rodney A. Stewart

Senior Lecturer, Griffith School of Engineering, Griffith University

Gold Coast Campus, Queensland 4222, Australia

r.stewart@griffith.edu.au

\section{Prof. Sherif Mohamed}

Professor, Griffith School of Engineering, Griffith University

Gold Coast Campus, Queensland 4222, Australia

s.mohamed@griffith.edu.au

\section{$\underline{\text { Citation Details }}$}

Panuwatwanich, K., Stewart ,R. A. and Mohamed, S. (2009) "Validation of an empirical model for innovation diffusion in Australian design firms", Construction Innovation, Vol. 9 No. 4, pp. 449-467. 


\section{Validation of an Empirical Model for Innovation Diffusion in Australian Design Firms}

\section{Structured Abstract}

Purpose - This paper is an extension to a previous empirical study that modelled the process of innovation diffusion in Australian architectural and engineering design (AED) firms. The present study utilised explanatory case studies to assist in the verification of this empirical model, which depicted pathways that explain the role of enabling 'climate for innovation' constructs in determining the level of innovation diffusion outcomes, and subsequent business performance in Australian AED firms.

Design/methodology/approach - This paper presents the latter of a two-stage sequential mixed method research design: (1) quantitative empirical study; and (2) qualitative explanatory case studies. Specifically, this stage extracted findings from five explanatory case studies using a qualitative pattern matching analysis technique. Interview-based data collected from the case studies were analysed to formulate the relationship patterns between constructs, which were then compared with those predicted by the empirical model. This approach afforded a determination on the extent to which the case-based findings (i.e. work-setting phenomena) explained (i.e. validated) the empirical model.

Findings - The results of the case studies on five Australian AED firms indicated that the model could be adequately explained by the actual phenomena. This was evident in four of the cases providing a good to perfect match, and one showing a partial match, to the predicted patterns of relationships between the model constructs. Thus, the paper presents verified empirical pathways for AED firms, which suggested that, by increasing the level of leadership for innovation, the level of team climate and organisational culture for innovation can be improved. The improved culture for innovation would then heighten the level of innovation diffusion outcomes, which could, in turn, result in an enhanced business performance.

Originality/value - This paper expanded and improved upon the current understanding of how the diffusion of innovation can be accelerated within the AED firm context. By focusing on the socio-psychological processes, the paper depicts the pathways to improved innovation diffusion outcomes and business performance, through fostering a robust climate for innovation. These pathways have been constructed empirically and were verified in this paper under real-work settings. Based on the validated model and the specific insights derived from the explanatory case studies, the paper also highlights a number of strategic implications for AED firms seeking to enhance their business performance through improving innovation diffusion practices.

Keywords - Architectural and engineering design, Australia, explanatory case studies, innovation diffusion, pattern matching

Paper type - Research paper 


\section{Background}

Innovation has been widely acknowledged as a modern source of competitive advantage for firms operating in the construction industry. According to Newton (1999), innovation is becoming a fourth competitive dimension in addition to the traditional time, cost and quality model. Realising the significance of innovation, many firms have expended significant amount of resources in an effort to acquire various forms of innovation in order to maintain and/or increase their competitiveness. Whilst some of these firms have been successful, many have not. The current lower than expected level of innovation in the construction industry has attracted many scholars to conduct research studies in an attempt to answer the question as to how, why and what causes such a success or failure. Despite such efforts, the field of innovation research within the construction organisation context has been considered to be very much in its embryonic stage (Sexton and Barrett, 2003). More studies are required to increase the current level of understanding of innovation within this particular context.

In the broader context, innovation is defined as any ideas, practices and technologies perceived to be new by the organisation involved (Van de Ven, 1986; Zaltman et al., 1973). Within the construction context, the definition of innovation has been more concerned with the successful development and/or implementation of new ideas, products, processes or practices in order to increase an organisations' efficiency and performance (Egbu et al., 1998; Ling, 2003; Sexton and Barrett, 2005). Both the successful development and implementation of innovation usually require effective bottom-up and top-down diffusion processes, respectively (Koskela and Vrijhoef, 2001; Winch, 1998). Diffusion, as defined by Rogers (2003), is the process in which innovation is communicated through certain channels among the members of a social system over time. Therefore, the diffusion of innovation has been viewed as hinging upon a sociopsychological process, as it is the product of social relationships and complex systems of interactions. Within an organisation, a socio-psychological process can manifest itself in the form of a 'climate', which can be perceived by an organisation's members, and is considered as a critical determinant of their motivation and behaviour (Kozlowski and Doherty, 1989). More specifically, 'climate for innovation' has been widely emphasised by management researchers as an important organisational element that can act as either a stimulant or an impediment to creativity and innovation (Ahmed, 1998; Ekvall, 1996). In the realm of construction research, such an issue has recently received attention from several researchers (see, for example, Dulaimi et al., 2005; Eaton et al., 2006; Egbu et al., 1998).

Past research studies have provided a great deal of knowledge regarding the critical factors and variables that influence the adoption and/or generation of innovation within construction organisations. More recently, research demand has shifted toward empirical studies that focus on the factors, and processes, that influence the actual implementation and diffusion of innovation, particularly, from a social perspective (Eaton et al., 2006; Ling, 2003; Peansupap and Walker, 2005; Stewart et al., 2004). However, more research is required that focuses on the context of 'design', which is an area being largely overlooked in many innovation studies, but is often recognised as the core construction industry sector where innovation invariably takes place (Salter and Torbett, 2003; Winch, 2003). 
This paper extends on a recent empirical study conducted by the authors (Panuwatwanich et al., 2008) in an effort to address the above-mentioned research gaps. The purpose of the present paper is to provide case-based evidence which serve as further validation of the key outcome of the prior study: an empirical model depicting relationships between the main socio-psychological constructs of the climate for innovation and their associated results. The paper is organised as follows. In the next section, the previously reported empirical model is briefly introduced and explained. Then, the research methodology undertaken to validate this model is described, followed by the presentation and discussion of the results. The final section provides implications and conclusions, with an accompanying section discussing possible future research directions.

\section{Model for Innovation Diffusion in Design Firms}

Inspired by the identified research gaps, the authors recently conducted an empirical study that focused on the social aspect of innovation diffusion within the AED firm context. To investigate this issue, a conceptual model incorporating three 'climate for innovation' constructs, namely, leadership for innovation (LFI), team climate for innovation (TCI), and organisational culture for innovation (OCI), along with two outcomeorientated constructs addressing innovation diffusion outcomes (IDO) and business performance (BPM), was developed. Statistical analyses, specifically, Exploratory Factor Analysis (EFA) and Structural Equation Modelling (SEM), were carried out using the data collected from a questionnaire survey of 181 design professionals, employed in Australian AED firms. EFA was initially conducted to uncover the factors representing each model construct. SEM was then employed to determine and confirm the factor structure of the model, and to assess the relationships between the model constructs. Table 1 summarises the model constructs and their associated factors identified from the EFA. Figure 1 illustrates the final empirical model derived from the SEM analysis. Readers are referred to Panuwatwanich et al. (2008) for the complete details of the model development and assessment procedures.

\section{INSERT TABLE 1}

\section{INSERT FIGURE 1}

According to the model, the LFI construct has a strong and positive influence on the TCI construct $(0.72, p<0.001)$, accounting for 51 percent of its variance $\left(R^{2}=0.51\right)$. Furthermore, both the LFI $(0.52, p<$ $0.001)$ and TCI $(0.35, p<0.01)$ constructs were found to positively influence the OCI construct, jointly explaining 65 percent of its variance $\left(R^{2}=0.65\right)$. The OCI construct, in turn, strongly and positively influences the IDO construct $(0.93, p<0.001)$, explaining 86 percent of its variance $\left(R^{2}=0.86\right)$. Finally, the BPM construct was found to be strongly influenced by the IDO construct $(0.77, p<0.001)$ with 59 percent of variance being accounted for $\left(R^{2}=0.59\right)$. The model implies that, by increasing the level of leadership for innovation, the level of both team climate and organisational culture for innovation can be improved. Moreover, an improvement in the organisational culture for innovation would, in turn, result in an increased level of innovation diffusion outcomes (measured by the innovativeness of design products, and the extent to 
which advanced technologies and innovative design practices were utilised). Furthermore, with improved outcomes from the innovation diffusion process, the firm's business performance, in terms of economic growth and client satisfaction, can be enhanced. Additionally, the model highlights the importance of developing conducive leadership for innovation in AED firms, as all the pathways that lead to improved outcomes from innovation diffusion and business performance emerged from the LFI construct.

Based on the abovementioned development and assessment procedures, as well as convincing statistical parameters, the model derived from the completed empirical study demonstrated high reliability and internal validity. However, to ensure its wider applicability, the model needed to also demonstrate a high level of external validity, which refers to the extent to which the model could be generalised to other settings, people or events (Sekaran, 2003). The following section details the research method undertaken to confirm the external validity of the model. Qualitative verification of empirical models provides the necessary triangulation to better model social systems such as these.

\section{Research Method}

Approach

In order to confirm the validity of the empirical model described above, a qualitative research approach was employed. The rationale behind this strategy followed sequential mixed method research design, whereby a quantitative study was firstly conducted, and the results obtained were then verified, using qualitative research techniques (Tashakkori and Teddlie, 1998). In the previous study, quantitative analysis, using a questionnaire survey, was carried out to produce the empirical model that represents the prevalent phenomena among Australian AED firms. A qualitative research approach was, therefore, adopted in the present study as a further step to help confirm the validity of the model. In doing so, this study employed a qualitative case study research method, as its focus was on a contemporary phenomenon within a natural AED firm setting (Yin, 2003). In particular, the explanatory power of case studies also helped to validate the empirical model, by means of establishing the external validity through an 'analytical generalisation'. This was carried out by using the model as a template to study several cases; the results of which were compared to determine whether the same findings and conclusions were obtained (Yin, 2003). The findings from the case studies were also used to help increase understanding on how representative the empirical model was of the current phenomena, thus paving the way for future research directions.

\section{Case study design}

Broadly, case studies can be classified as descriptive, exploratory and explanatory: descriptive case studies focus on determining what needs to be described, which may be simply what the researcher gathered about the situation; exploratory case studies usually focus on theory and/or hypothesis development; and explanatory case studies focus on theory and/or hypothesis testing (McCutcheon and Meredith, 1993; Yin, 2003). For the purpose of this study, the explanatory approach was adopted since the aim was to validate the empirically developed model. By following this approach, the model was treated as a set of propositions to be tested. In addition, this study adopted multiple case studies design, since its replication logic allowed the 
analytical generalisation to be conducted (Darke et al., 1998; Yin, 2003). The selection of the firms to be included in the case studies was based on similar criteria used in the quantitative analysis (i.e. model assessment) conducted in the previous study: (1) the firm should have at least 10 employees; (2) the firm's main scope of work should include the design of buildings and/or infrastructure; and (3) the firm should operate as a private business. For the purpose of time and cost efficiency, the sampling frame for the case studies was limited to firms that had offices in the cities of Brisbane or the Gold Coast, Australia, where the authors were based.

\section{Data collection}

Case studies usually involve the combination of various data collection methods, such as archives, interviews, questionnaires and observations, to ensure the internal validity of the results (Eisenhardt, 1989, Yin, 2003). The present study relied on two main data sources: interviews and documentation. Semistructured interviews, in particular, were used to maximise the flexibility of the interview, and provide the capacity to tailor the interview to suit the individual (Nicholson and Kiel, 2007). To obtain a complete and accurate description of the interviewee's responses and comments, all interviews were recorded and transcribed. Face-to-face interviews were chosen to provide the opportunity for clarifying ambiguous questions, as well as to observe the actual environment of the firm being studied. During each interview, an interview guide was used to maintain the direction of the conversation and the relevant lines of enquiry, whilst probing into the issues of interest. The interview guide was developed based on a set of measures derived from the factor analysis carried out in the previous study. Its purpose was to ensure that the data collected from the case studies were comparable to those obtained from the previous questionnaire survey, thus enabling the more precise validation of the empirical model. Lastly, to improve the internal validity of the case study results, documentation in the form of the firms' internal newsletters, profile and information sheets, as well as other online documents, were obtained to supplement the findings from the interviews.

\section{Data analysis}

Generally, data analysis consists of examining, categorising, tabulating, testing or otherwise recombining evidence to address the initial propositions of a study (Yin, 2003). Following the procedures recommended by Eisenhardt (1989), the data analysis for the present study consisted of two key steps: within-case and cross-case analyses. The within-case analysis was concerned with the evaluation of the collected data, as well as the reporting of the findings of each individual case study. The information gained from each case provided an insight into how the model factors and constructs were perceived within a real-life context. This was presented in the form of a qualitative rating of such factors and constructs. The within-case analysis began with data organisation, by assigning each piece of evidence (all in a documentary format) a reference number. Using a descriptive coding, the evidence's contents were coded such that they could be classified into relevant factors of the model (Miles and Huberman, 1989). Following the coding process, the analysis proceeded with documenting all the coded information in an evidentiary-based manner, using Miles and Huberman's (1989) tabular approach. This approach involved creating a matrix of categories representing model factors and placing the evidence within such categories. 
Once all the evidence had been organised into the relevant model factors, they were evaluated through a systematic rating procedure; whereby each of the factors was classified, based on its corresponding evidence, into one of the following value descriptors: high; medium; and low. To ensure the reliability and consistency of the rating, a set of qualitative assessment rubrics (an assessment tool used extensively in the field of education) was developed to serve as the criteria for classifying the factors into one of the above three descriptors. Table 2 presents the qualitative assessment rubric for the TCI construct. Similar rubrics for the other constructs are not presented due to paper size constraints. For a factor to take on a particular value descriptor, the evidence provided for that factor should demonstrate a close match to the feature described within such a descriptor. After the individual factors had been rated, they were qualitatively totalled to represent the overall rating level of their respective construct (cf. Zinatelli et al., 1996).

\section{INSERT TABLE 2}

Following the within-case analysis was an examination of cross-case patterns (i.e. cross-case analysis). The aim of the cross-case analysis was to validate the conclusions drawn from the multiple-case studies through the 'pattern matching' technique (McCutcheon and Meredith, 1993). Fundamentally, a pattern matching is used to link the collected data to the theoretical propositions, by comparing the pattern of the actual values of variables to those predicted by the propositions (McCutcheon and Meredith, 1993; Yin, 2003). According to Mitchell and Bernauer (1998), the use of such a technique makes it explicit about what the model predicts in the cases at hand, and draws attention to the degree to which the constructs correlate as predicted. For the purposes of this study, the pattern matching compared the patterns of relationships between the rated constructs, with those predicted by the empirical model. Therefore, the development of a set of relationship patterns predicted by the model was required prior to conducting the cross-case analysis (Nicholson and Kiel, 2007). It is worth mentioning that the pattern-matching procedure involves no precise comparisons; there may not be quantitative or statistical criteria involved on which to judge the pattern, thus allowing for some interpretive discretion on the part of the researcher (Yin, 2003). In view of this, the present study followed Yin's (2003) suggestion by avoiding the postulation of very subtle patterns, to ensure that the pattern matching only deals with either gross matches or mismatches.

Based on the empirical model presented earlier (Figure 1), the predicted patterns were developed using the three value descriptors (i.e. high, medium, and low) for the exogenous construct (i.e. LFI). The values of the corresponding endogenous constructs (i.e. TCI, OCI, IDO and BPM), were determined by following the paths depicted in the model, and by taking into account the standardised path coefficients. Specifically, as presented in Table 3, these coefficients were classified on the basis of Cohen's (1988) effect size criteria as: small $(0.10-0.29)$; medium $(0.30-0.49)$; and large $(\geq 0.50)$. As a result, three main predicted patterns were developed (Figure 2). 
INSERT FIGURE 2

According to Figure 2, the model predicted that a higher level of LFI will lead to a higher level of TCI. Also, achieving higher levels of both constructs together will substantially lead to a higher level of OCI, with LFI having a stronger effect than TCI. Subsequently, the higher level of OCI will lead to a higher level of IDO, which will in turn contribute to a higher level of BPM. In the same manner, a lower level of LFI will result in a lower level of TCI and OCI, which leads to a lower level of IDO and, eventually, a lower level of BPM.

Finally, once the matching results of all cases had been obtained, the judgement regarding whether the developed model can be validated by the case studies was then made based on the extent to which the cases matched predicted patterns. If the matching results demonstrated that most of the case-based patterns have a good or perfect match with the predicted patterns, the model is considered to be well explained (i.e. it can be qualitatively validated by the case studies). Conversely, if most of the results show a poor match, the model cannot be validated by the case studies.

\section{Results}

Case studies were conducted with five Australian AED firms, between December 2007 and April 2008. For the purpose of confidentiality, the five case study participants were referred to as firms A, B, C, D and E to maintain their anonymity. The case study profiles of all firms, in terms of the number of employees, areas of expertise, scope of operation, as well as the details of the interview participants and locations, are summarised in Table 4.

\section{INSERT TABLE 4}

Overall, the case studies comprised a good mix of firms of different types. As Table 4 shows, the size of the firms, in terms of the number of employees, ranged from 100-360 employees. Firms A and B provided engineering consultancy, whereas firms C, D and E provided architectural design, as their main services. The scope of operation of these firms ranged from regional to international, with multiple offices. In total, 19 design professionals, comprising four design team members from each of the firms $\mathrm{A}, \mathrm{B}, \mathrm{C}$ and $\mathrm{D}$, and three members from firm E, participated in the interviews. The duration of each interview ranged from 20 to 60 minutes, with an average of 40 minutes. Four sets of interviews were conducted in Brisbane, and one was conducted in the Gold Coast, Australia. All interviews were carried out by the first author of this paper on a one-to-one basis. 
A sample extract containing the qualitative findings and rating results for the case of the TCI construct in firm A is presented in Table 5 to illustrate the analysis procedures underpinning the within-case analysis results. From the table, the details of the 'descriptive summary' of each factor were compared with the developed TCI construct rubric (Table 2) to determine which value descriptor could best explain the factor. For example, the descriptive summary of the 'vision' factor was rated as 'high' since the focal team appeared to have achievable goals that were understood and valued by team members, which best matched the criteria for the 'high' value descriptor of the rubric. Once all factors had been rated, they were totalled to represent the overall rating level for the TCI construct (i.e. high). Although the 'task orientation' factor was rated as medium, the overall rating level was outweighed by the high rating levels of the other three factors. Similar rating procedures were carried out for all factors and constructs for all cases.

Table 6 summarises the within-case analysis results for all five case studies. More specifically, the table shows, for each case, the overall rating for the five constructs (LFI, TCI, OCI, IDO and BPM), and their corresponding rated factors derived from the qualitative findings.

\section{INSERT TABLE 6}

In addition to demonstrating the rating levels for each case, the within-case results provided an indication regarding the reliability of the rated factors in representing the model constructs. According to Table 6, most of the factors within each construct seem to consistently and positively correlate with one another, across all cases. In particular, within the BPM construct, the correlations between the two factors were high and consistent across all five cases. Similarly for LFI, OCI and IDO, most of the factors within these constructs appear to be well correlated with one another, particularly those in the case of firms A and E. In other cases, at least two out of three factors are highly correlated. Within the TCI construct, whilst most factors appear to be highly correlated in almost all cases, only the results of firm D show a lack of correlation between the factors. However, this minor discrepancy does not weaken the validity of the measurement model, as this appears to be the only anomaly which surfaced during the within-case analysis. Overall, the model factors proved to be adequately reliable in capturing the qualitative rating level of the constructs, thus lending support for the robustness of the model's factor structure uncovered in the previous study (see Table $1)$.

Table 7 presents the cross-case analysis results, in terms of the qualitative rating for the constructs and a systematic assessment as to whether the cases matched the predicted patterns. For ease of interpretation, the results are presented in order, based on how well the case-based pattern matches the predicted pattern (i.e. from a perfect match to a partial match). As the table shows, the relationship patterns of the rated constructs in the case of firms A and E show a perfect match to Predicted Pattern 1 (Figure 2). At both firms, the level of LFI (high) indicates a strong correlation with the level of TCI (high). As predicted, both of 
the constructs appear to be associated with the level of OCI (high), which, in turn, corresponds with the level of IDO (high). Moreover, the patterns of both cases indicate that the level of OCI (high) correlates with the level of BPM (high). In summary, for both of these firms, the patterns perfectly matched Predicted Pattern 1.

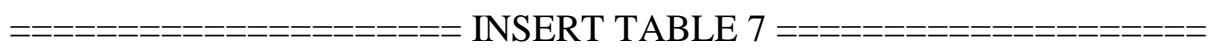

In the case of firm C, the level of LFI (medium) seems to have a strengthening effect on the level of TCI (high), which does not correspond with the relationship predicted. The level of both constructs also appear to correlate with the level of OCI (high), but with TCI showing a stronger association with this construct instead of LFI. Such a pattern of relationships, however, corresponds partly with the model prediction, which specified that LFI has a stronger effect than TCI in influencing OCI (Figure 2). Despite this minor discrepancy, the remaining relationship patterns were found to match Predicted Pattern 1, showing that the level of OCI (high) correlates with the level of IDO (high), which then correlates with the level of BPM (high). Since the overall relationship pattern seems to explain most of the relationships stipulated in the model, the case study results for firm $\mathrm{C}$ were considered to have a good match with Predicted Pattern 1.

The results of the case study of firm D indicate that the level of LFI (high) has a weakening effect on the level of TCI (medium), showing these constructs do not correlate as expected. Moreover, although the level of TCI (medium) correlates well with the level of OCI (medium) as expected, this relationship seems to be stronger than that between the level of LFI and OCI, which does not entirely match the model prediction (Figure 2). Despite this anomaly, the level of OCI (medium) appears to strongly correlate with the level of IDO (medium), which, in turn, shows a strong correlation with the level of BPM (medium). Evidently, these relationships (i.e. OCI $\rightarrow$ IDO $\rightarrow$ BPM) correspond with those specified in the model (Predicted Pattern 2). Accordingly, it can be concluded that the overall pattern of relationships between the constructs identified in firm D has a good match to Predicted Pattern 2.

Finally, the relationship patterns of the constructs at firm B indicates that the level of LFI (high) strongly correlates with the level of TCI (high) as predicted. The levels of both constructs, however, do not seem to correlate with the level of OCI (medium). Despite this mismatch, the level of OCI shows a strong correlation with the level of IDO (medium), which, in turn, highly correlates with the level of BPM (medium). This pattern of relationships (i.e. OCI $\rightarrow$ IDO $\rightarrow$ BPM), therefore, demonstrates a match to Predicted Pattern 2. However, as this is the only part of the pattern that corresponds well with such a prediction, the case-based pattern identified in firm B was considered to have only a partial match to Predicted Pattern 2. 


\section{Discussion}

Overall, the results suggested that the relationships between the constructs depicted in the model could be adequately explained by the case studies. In total, four cases had a good to perfect match with the predicted patterns, with the remaining case having a partial match. More specifically, there were two cases (firms A and E) showing a perfect match, and one case (firm C) showing a good match to Predicted Pattern 1. One case (firm D) showed a good match, and one (firm B) showed a partial match, to Predicted Pattern 2. Based on the cross-case pattern matching results, the following paragraphs provide a detailed discussion regarding the relationships among the five model constructs.

\section{Relationships between the three climate constructs}

For the case of firms A, B and E, a strong correlation between the LFI and TCI constructs provides support that the leadership for innovation strongly influences the team climate for innovation. This potential causal relationship was corroborated by comments from most of the interviewed junior engineers and architects, that their supervisors/team leaders greatly influenced the innovation-conducive climate within their teams. More specifically, in order to create such a climate, they strongly agreed that supervisors should emphasise an inclusive team environment, and should be willing to listen to different ideas from team members.

This relationship, however, was not supported in the case of firms C and D, as it was found that the LFI construct did not appear to influence the TCI construct. Perhaps, this anomaly can be explained under two circumstances. Firstly, at firm C, the moderate rating level for the LFI construct was deduced from the medium rating levels for the 'innovation championing' and 'creativity stimulation and inspiration' factors, as well as the high rating level for the 'engagement and support' factor (see Table 6). When considering the above comments from the junior designers, this might be the case that the level of team climate for innovation in this firm was influenced more by the level of engagement and support of the supervisors, rather than by the other two factors. Secondly, by re-examining the case of firm D, it was found that the team under investigation was made up of some new members, mostly trainee architects. Naturally, new members tend to have less communication and bonds, thus resulting in the team being less cohesive. The trainee architects, in particular, are more likely to have less commitment and dedication to the team, according to one of the design associates. As such, the effect of team composition might be a potential factor that explains why the level of team climate did not correspond with the high level of leadership for innovation in this firm.

The results of firms A and E fully supported the prediction that the OCI construct will be positively influenced by the LFI and TCI constructs. The participants from both firms pointed out that innovative leaders and teams definitely have an influence on the firms' culture of innovation. For example, the senior engineer from firm A mentioned that the firm will try to provide full support if team members express their intention to advance their knowledge, skills and abilities. In other words, the more strongly the team shows willingness to innovate, the higher the level of support provided by the firm. Additionally, an interviewed architect from firm E believed that the improvement of the firm's culture for innovation over the last few years has been a result of improved supportive policies and systems, which were introduced by the top 
managers. This implied that the supervisors with strong leadership for innovation can potentially increase the level of organisational culture for innovation.

At firms $\mathrm{C}$ and $\mathrm{D}$, the above relationships were partially upheld since the rating level of the OCI construct in both firms seems to be strongly associated only with the rating level of the TCI construct, but not with that of the LFI construct. At firm C, this unexpected result may be explicated by an earlier presumption that 'engagement and support' could be an influential factor of the LFI construct in this firm. This observation appeared to be corroborated by the inspection of firm C's rating results (Table 6), which revealed that the level of such a factor appears to correlate strongly with the high rating level of the 'freedom and autonomy' and 'innovation support and facilitation' factors of the OCI construct. Turning to firm D, the lack of association between the LFI and OCI constructs may be explained by the fact that, over the last three years, several directors who were regarded as prominent architects had departed the firm. Such a significant loss of key personnel had interrupted the business process in such a way that the firm purposely, or unknowingly, readjusted its business strategy to one which was less inclined to be as innovative as it used to be. This could explain the lower than expected culture for innovation. In this case, although the current supervisors had a high level of leadership for innovation, they were unlikely to influence an improved culture for innovation, unless the firm regains its business stability and restores its innovation-oriented strategy.

In the case of firm B, the results indicated that the OCI construct did not seem to be influenced by both the LFI and TCI constructs as anticipated. A further examination into the case revealed that such a mismatch may be due to the fact that the firm had recently undergone a management restructure, which was aimed to improve the capability of the firm. Although the change led to the recruitment of a number of personnel to form innovative teams, the dismissal of a few ineffective managers, as well as the appointment of several innovative leaders, it is unlikely that such a change would have translated into an improved culture for innovation in the short term. However, the engineering manager who took part in championing the restructuring process believed that such a change has started to drive the firm towards an improved culture for innovation, by being more flexible, supportive, and more inclined to use innovative approaches in carrying out the projects. It can thus be inferred that such an anomaly in firm B might be attributable to an organisational lag, i.e. the discrepancy in the rate at which a change in an organisation affects certain outcomes.

\section{Innovation diffusion outcomes and business performance}

The findings from the case studies provided a strong support for the prediction that the IDO construct will be influenced by the OCI construct. This causal relationship was corroborated by the opinions of most interviewed participants. At firm A, the interviewed engineers believed that by instilling a 'think beyond the square' culture, the firm can consistently introduce innovative solutions and is always ahead in utilising advanced engineering technologies. By improving the culture to be more flexible and adaptive, the engineering manager from firm $B$ believed that the firm is employing more advanced technologies/techniques, and is likely to deliver better innovative outcomes. The interviewed architects from 
firm $\mathrm{C}$ mentioned that, by having a culture that is inclusive and supportive, new ideas and knowledge can be quickly diffused and implemented to produce high quality design products. In the same manner, the design associate from firm D observed that, with the recent change in its business strategy resulting in a decreased culture of innovation, the firm tended to be less active in delivering innovative design. Finally, the junior architect from firm E reasoned that, by having a culture that is very supportive and strongly encourages innovation, the firm is always at the forefront of architectural innovativeness.

The results from all cases also confirmed that the IDO construct will influence the BPM construct. This relationship can be exemplified by comments made by the participants from firms A, C and E, that the high level of their firm's innovativeness has helped them to maintain their business competitiveness and the high level of client satisfaction. In particular, by realising a potential benefit of being innovative, firm B reengineered itself with the confidence that the level of innovation diffusion outcomes will be improved, and will ultimately result in an increased level of business competitiveness. On the other hand, by being less active in generating and adopting innovation, the design associate at firm $\mathrm{D}$ believed that the firm has lost some reputation and market share over the last few years.

In summary, the findings from the explanatory case studies of five Australian AED firms provided support that the empirically developed model can be adequately explained (i.e. validated), by the actual relationships between the climate constructs, and their contributions towards innovation-related outcomes. This was evident from the results of four cases indicating a good to perfect match, and one case indicating a partial match to the developed predicted patterns. It was also found that the causes of the slight mismatch between the case-based patterns and the predicted patterns were mainly attributable to several factors not addressed in the model, which include: team compositions; changes in business strategy and management structure; and organisational lag. These factors may, indeed, account for a certain extent of unexplained variance which existed in the empirical model (as seen from the $R^{2}$ values Figure 1). By taking this fact into account, the validity of the empirical model was reasonably confirmed by the findings from the case studies, as the model has been shown to be representative of the actual phenomena among the sampled firms.

\section{Implications}

Besides demonstrating the validity of the empirically developed model, the present study also provides a number of strategic implications for design firms seeking to improve their business performance through innovation. Based on both the empirical model and the findings from the case studies, these implications are summarised below.

- Firstly, to ensure that the innovation will contribute to the improved business performance, firms should monitor their ability to effectively diffuse innovation by: (1) assessing how well they generally perform in harnessing and turning creative ideas into innovative design solutions; and (2) assessing how effective they are in utilising the adopted design technologies/techniques. 
- Secondly, to improve the diffusion of innovation, firms should ensure that the culture for innovation prevails. Within such a culture, creative ideas are more likely to be better transformed into innovative solutions. Likewise, the adopted technologies/techniques are more likely to be better diffused and exploited among members of the firms.

- Thirdly, to improve or create a culture for innovation, firms should place an emphasis on developing leaders whose behaviours favour innovation. Directly, these leaders can shape an innovation culture by championing policies and practices that accelerate the diffusion of innovation. Indirectly, they can influence the improved climate for innovation among teams, which will in turn become an important building block for the firms' culture for innovation.

- Lastly, to sustain the culture for innovation, firms should emphasise the issue of human capital. In particular, firms should work hard to retain innovative people and minimise their staff turnover rate, since an unstable employee composition, as much as disrupting their business operations, can: (1) lead to a decreased climate for innovation among teams, which could eventually result in a decreased innovation culture; and (2) adversely affect the firm's business strategy such that it leads to the innovation culture being suppressed.

\section{Conclusion}

This paper presents a study, which was undertaken to validate a previously developed empirical model for innovation diffusion in Australian AED firms. To achieve this objective, the study employed a qualitative research approach, particularly, an explanatory case study method. Multiple case studies were conducted with five Australian AED firms through semi-structured, face-to-face interviews with 19 design professionals. The results from the case studies provided two important findings which supported the validity of the empirical model. Firstly, the results from the within-case analysis showed that almost all model factors representing the constructs were consistently correlated across all the sampled firms. This finding indicated that the factors were adequately reliable in measuring the actual phenomena, thus reinforcing the robustness of the model's factor structure uncovered in the previous study. Secondly, the overall finding from the crosscase analysis, utilising the pattern matching technique, showed a strong correlation between the quantitatively and qualitatively represented patterns of construct relationships. This finding indicated that the empirical model can be well explained (i.e. validated) by the qualitative findings from the case studies. Finally, based on the validated empirical model and insights from the case studies, the study also provides practical recommendations for design firms to enhance their innovation diffusion practices by: creating a culture for innovation through cultivating innovative leaders, and sustaining such a culture by being committed to the issue of human capital, in order to retain innovative people and stabilise the employee composition. 


\section{Future Research}

Despite following a rigorous two-stage sequential mixed method research design, the findings from the present and previously reported study could be further strengthened in a number of ways. Firstly, to enhance the ability of the case studies in verifying the empirical model, future research should attempt to conduct a larger number of case studies, with greater numbers of interviewees, in a variety of firms of different sizes. Secondly, to accommodate the effect of the identified organisational lag, future research should consider conducting longitudinal case studies to better assess the innovation diffusion phenomena in AED firms. Thirdly, as one of the case studies indicated that some factors might better represent their underlying construct than others, further data analysis, on which specific factors within each construct leverages specific outcome-orientated factors, could be undertaken to improve the explanatory power of the model. For example, the analysis could employ stepwise regression and path analysis to pinpoint the most influential factors within each model construct, and to then ascertain the links between such factors. Finally, future research should attempt to re-examine the model using the 'System Dynamic (SD)' approach. By applying the SD concept, the model would be able to portray the process of interaction and feedback among the model constructs, thus better addressing the real-time dynamics of innovation processes and organisational reality. In doing so, further empirical analysis may be needed to examine the relationships between the current model constructs and other organisational aspects which are closely related to innovation diffusion, namely, organisational learning and knowledge management practices. The proposed studies are essential for the continuous advancement of the body of knowledge addressing the innovation diffusion phenomena in the construction industry.

\section{References}

Ahmed, P. K. (1998), 'Culture and climate for innovation', European Journal of Innovation Management, Vol. 1 No. 1, pp. 30-43.

Cohen, J. (1988), Statistical Power Analysis for the Behavioral Sciences, 2nd edn, L. Erlbaum Associates, Hillsdale, N.J.

Darke, P., Shanks, G. and Broadbent, M. (1998), 'Successfully completing case study research: combining rigour, relevance and pragmatism', Information Systems Journal, Vol. 8 No. 4, pp. 273-289.

Dulaimi, M. F., Nepal, M. P. and Park, M. (2005), 'A hierarchical structural model of assessing innovation and project performance', Construction Management and Economics, Vol. 23 No. 6, pp. 565-577.

Eaton, D., Akbiyikli, R. and Dickinson, M. (2006), 'An evaluation of the stimulants and impediments to innovation within PFI/PPP projects', Construction Innovation, Vol. 6 No. 2, pp. 63-77.

Egbu, C. O., Henry, J., Kaye, G. R., Quintas, P., Schumacher, T. R. and Young, B. A. (1998), 'Managing organizational innovations in construction', Proceedings of the 14th Annual Conference of the Association of Researchers in Construction Management (ARCOM), ed. W. Hughes, Reading, pp. 605-614.

Eisenhardt, K. M. (1989), 'Building theories from case study research', The Academy of Management Review, Vol. 14 No. 4, pp. 532-550. 
Ekvall, G. (1996), 'Organizational climate for creativity and innovation', European Journal of Work and Organizational Psychology, Vol. 5 No. 1, pp. 105-123.

Koskela, L. and Vrijhoef, R. (2001), 'Is the current theory of construction a hindrance to innovation?' Building Research and Information, Vol. 29 No. 3, pp. 197-207.

Kozlowski, S. W. J. and Doherty, M. L. (1989), 'Integration of climate and leadership: examination of a neglected issue', Journal of Applied Psychology, Vol. 74 No. 4, pp. 546-553.

Ling, F. Y. Y. (2003), 'Managing the implementation of construction innovations', Construction Management and Economics, Vol. 21 No. 6, pp. 635-649.

McCutcheon, D. M. and Meredith, J. R. (1993), 'Conducting case study research in operations management', Journal of Operations Management, Vol. 11 No. 3, pp. 239-256.

Miles, M. B. and Huberman, A. M. (1989), Qualitative Data Analysis: A Source Book of New Methods, SAGE Publications, Newbury Park.

Mitchell, R. and Bernauer, T. (1998), 'Empirical research on international environmental policy: designing qualitative case studies', Journal of Environmental and Development, Vol. 7 No. 1, pp. 4-31.

Newton, P. W. (1999), 'Modelling innovation in AEC: understanding the fourth dimension of competition', available at: http://www.ce.berkeley.edu/ tommelein/CEMworkshop/Newton.pdf.

Nicholson, G. J. and Kiel, G. C. (2007), 'Can directors impact performance? A case-based test of three theories of corporate governance', Corporate Governance, Vol. 15 No. 4, pp. 585-608.

Panuwatwanich, K., Stewart, R. A. and Mohamed, S. (2008), 'The role of climate for innovation in enhancing business performance: the case of design firms', Engineering, Construction and Architectural Management, Vol. 15 No. 5 pp. 407- 422.

Peansupap, V. and Walker, D. H. T. (2005), 'Factors enabling information and communication technology diffusion and actual implementation in construction organisations', Electronic Journal of Information Technology in Construction, Vol. 10, pp. 193-218.

Rogers, E. M. (2003), Diffusion of Innovations, 5th edn, Free Press, New York.

Salter, A. and Torbett, R. (2003), 'Innovation and performance in engineering design', Construction Management and Economics, Vol. 21 No. 6, pp. 573-580.

Sekaran, U. (2003), Research Methods for Business: A Skill-Building Approach, 4th edn, Wiley, New York.

Sexton, M. and Barrett, P. (2003), 'A literature synthesis of innovation in small construction firms: insights, ambiguities and questions', Construction Management and Economics, Vol. 21 No. 6, pp. 613-622.

Sexton, M. and Barrett, P. (2005), 'Performance-based building and innovation: balancing client and industry needs', Building Research and Information, Vol. 33 No. 2, pp. 142-148.

Stewart, R. A., Mohamed, S. and Marosszeky, M. (2004), 'An empirical investigation into the link between information technology implementation barriers and coping strategies in the Australian construction industry', Construction Innovation, Vol. 4 No. 3, pp. 155-171.

Tashakkori, A. and Teddlie, C. (1998), Mixed Methodology: Combining Qualitative and Quantitative Approaches, SAGE Publications, Thousand Oaks.

Van de Ven, A. H. (1986), 'Central problems in the management of innovation', Management Science, Vol. 32 No. 5, pp. 590-607. 
Winch, G. (1998), Zephyrs of creative destruction: understanding the management of innovation in construction', Building Research and Information, Vol. 26 No. 4, pp. 268-279.

Winch, G. (2003), 'How innovative is construction? Comparing aggregated data on construction innovation and other sectors - a case of apples and pears', Construction Management and Economics, Vol. 21 No. 6, pp. 651-654.

Yin, R. K. (2003), Case Study Research: Design and Methods, 3rd edn, SAGE Publications, Thousand Oaks.

Zaltman, G., Duncan, R. and Holbek, J. (1973), Innovations and Organizations, Wiley, New York.

Zinatelli, N., Cragg, P. B. and Cavaye, A. L. M. (1996), 'End user computer sophistication and success in small firms', European Journal of Information Systems, Vol. 5, pp. 172-181. 


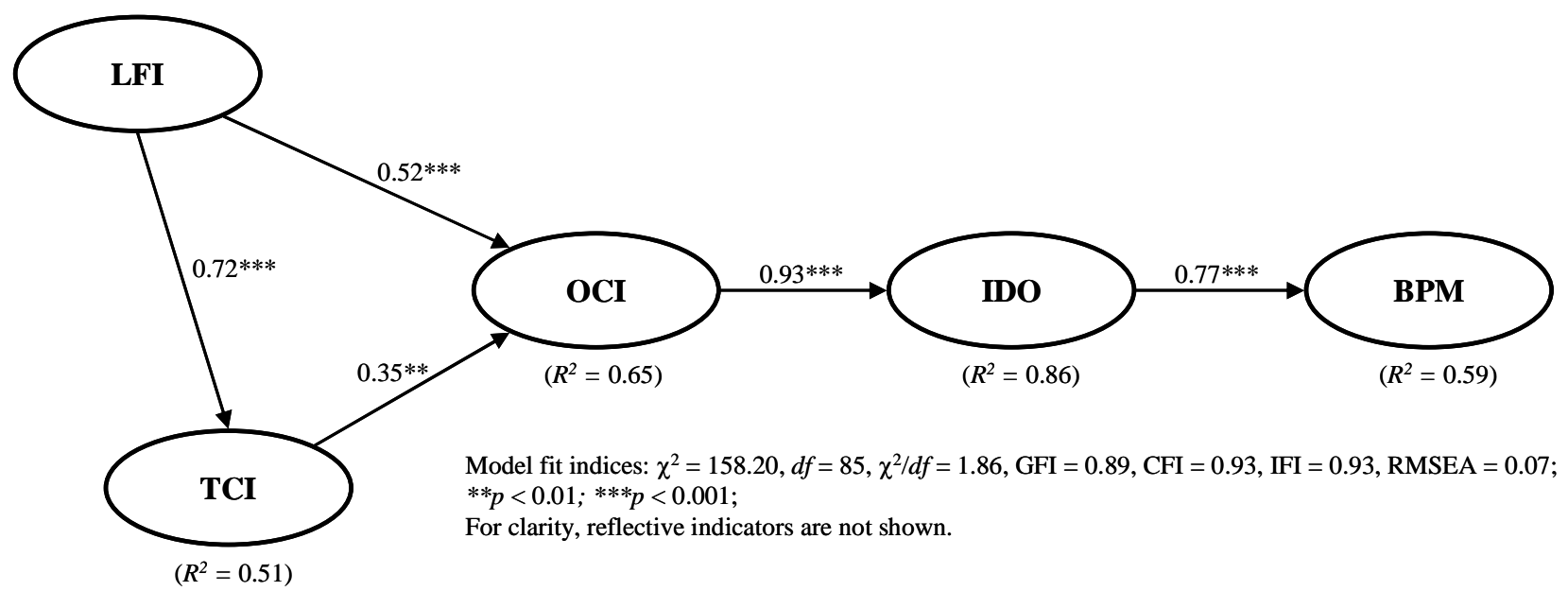

Figure 1 Empirical model for innovation diffusion in AED firms (Panuwatwanich et al., 2008) 


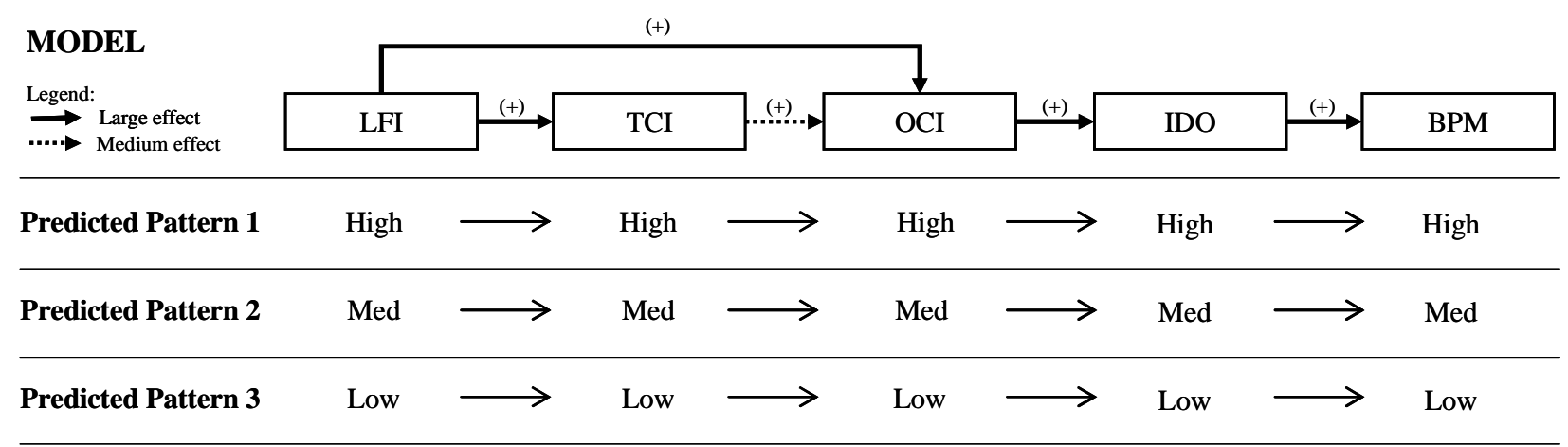

Figure 2 Predicted patterns of relationships between model constructs 
Table 1 Model constructs and associated factors (Panuwatwanich et al., 2008)

\begin{tabular}{ll}
\hline Construct & Factor details \\
\hline $\begin{array}{l}\text { Leadership for innovation (LFI) } \\
(=.88)\end{array}$ & LFI1: Innovation championing \\
& LFI2: Creativity stimulation and inspiration \\
& LFI3: Engagement and support \\
Team climate for innovation (TCI) & TCI1: Vision \\
$(\alpha=0.87)$ & TCI2: Participative safety \\
& TCI3: Task orientation \\
& TCI4: Support for innovation \\
& \\
$\begin{array}{l}\text { Organisational culture for innovation (OCI) } \\
(\alpha=0.86)\end{array}$ & OCI1: Propensity for creativity \\
& OCI2: Freedom and autonomy \\
OCI3: Innovation support and facilitation \\
Innovation diffusion outcomes (IDO) & IDO1: Innovative design products \\
$(\alpha=0.83)$ & IDO2: Innovative design practices \\
& IDO3: Advanced technology utilisation \\
Business performance (BPM) & BPM1: Economic growth \\
$(\alpha=0.83)$ & BPM2: Client satisfaction
\end{tabular}

Note: $\alpha$ denotes Cronbach's alpha (coefficient of reliability) 
Table 2 Qualitative assessment rubric for the TCI construct

\begin{tabular}{|c|c|c|c|}
\hline \multirow{2}{*}{ Factors } & \multicolumn{3}{|c|}{ Rating criteria } \\
\hline & High & Medium & Low \\
\hline Vision & $\begin{array}{l}\text { Realistic or achievable } \\
\text { goals/targets are usually set } \\
\text { and are highly valued by all } \\
\text { team members. } \\
\text { Clear goals/targets are } \\
\text { usually explained and/or } \\
\text { presented in such a way } \\
\text { that they can be understood } \\
\text { by all team members. }\end{array}$ & $\begin{array}{l}\text { Goals/targets are set but } \\
\text { sometimes difficult to } \\
\text { achieve. } \\
\text { Goals/targets are fairly well } \\
\text { explained and team } \\
\text { members seem to know } \\
\text { some aspects of what needs } \\
\text { to be achieved. }\end{array}$ & $\begin{array}{l}\text { Goals/targets are rarely } \\
\text { mentioned to all team } \\
\text { members. } \\
\text { Team members do not have } \\
\text { a clear picture regarding } \\
\text { what and when a certain } \\
\text { task needs to be achieved. }\end{array}$ \\
\hline $\begin{array}{l}\text { Participative } \\
\text { Safety }\end{array}$ & $\begin{array}{l}\text { - Team displays a very strong } \\
\text { sense of togetherness. } \\
\text { Team members understand } \\
\text { and accept each other very } \\
\text { well. } \\
\text { - Team members continually } \\
\text { keep each other informed. }\end{array}$ & $\begin{array}{l}\text { Team displays some sense } \\
\text { of togetherness. } \\
\text { Team members understand } \\
\text { and accept each other quite } \\
\text { well. } \\
\text { Team members keep each } \\
\text { other informed every now } \\
\text { and then. }\end{array}$ & $\begin{array}{l}\text { Team lacks a sense of } \\
\text { togetherness. } \\
\text { Team members have a } \\
\text { problem understanding and } \\
\text { working with each other. } \\
\text { Team members usually } \\
\text { work independently and do } \\
\text { not regularly communicate } \\
\text { to keep each other } \\
\text { informed. }\end{array}$ \\
\hline $\begin{array}{l}\text { Task } \\
\text { Orientation }\end{array}$ & $\begin{array}{l}\text { Team always builds on } \\
\text { everyone's ideas to achieve } \\
\text { the best possible outcomes. } \\
\text { Team always assesses its } \\
\text { weaknesses and tries to } \\
\text { improve them to achieve } \\
\text { better outcomes. }\end{array}$ & $\begin{array}{l}\text { Team tries to build on } \\
\text { everyone's ideas to achieve } \\
\text { the best possible outcomes. } \\
\text { Team is aware of its } \\
\text { weaknesses and sometimes } \\
\text { tries to improve them. }\end{array}$ & $\begin{array}{l}\text { - Team rarely attempts to } \\
\text { engage everyone's ideas to } \\
\text { achieve the best possible } \\
\text { outcomes. } \\
\text { - Team rarely discusses its } \\
\text { weaknesses in an open } \\
\text { manner. }\end{array}$ \\
\hline $\begin{array}{l}\text { Support for } \\
\text { Innovation }\end{array}$ & $\begin{array}{l}\text { Team always searches for } \\
\text { new ideas/ approaches for } \\
\text { solving problems. } \\
\text { Team always spends time } \\
\text { working on new ideas. } \\
\text { Everyone in the team } \\
\text { consistently helps and } \\
\text { supports each other to } \\
\text { develop and try out new } \\
\text { ideas. }\end{array}$ & $\begin{array}{l}\text { Team sometimes searches } \\
\text { for new ideas/ approaches } \\
\text { for solving problems. } \\
\text { Team occasionally spends } \\
\text { time working on new ideas. } \\
\text { Team members sometimes } \\
\text { try to help and support each } \\
\text { other to develop and try out } \\
\text { new ideas. }\end{array}$ & $\begin{array}{l}\text { Team rarely or never } \\
\text { searches for new ideas/ } \\
\text { approaches for solving } \\
\text { problems. } \\
\text { Team rarely or never } \\
\text { spends time working on } \\
\text { new ideas. } \\
\text { Most of the team members } \\
\text { work individually and do } \\
\text { not usually support each } \\
\text { other in developing or } \\
\text { trying out new ideas. }\end{array}$ \\
\hline
\end{tabular}


Table 3 Classification of effect sizes for relationships between model constructs

\begin{tabular}{lll}
\hline Relationship & $\begin{array}{l}\text { Standardised path coefficient }- \\
\text { empirical model }\end{array}$ & $\begin{array}{l}\text { Classification of effect size based } \\
\text { on Cohen's criteria }\end{array}$ \\
\hline LFI $\rightarrow$ TCI & 0.72 & Large effect \\
LFI $\rightarrow$ OCI & 0.52 & Large effect \\
TCI $\rightarrow$ OCI & 0.35 & Medium effect \\
OCI $\rightarrow$ IDO & 0.93 & Large effect \\
IDO $\rightarrow$ BPM & 0.77 & Large effect \\
\hline
\end{tabular}

${ }^{\dagger}$ Cohen's effect size criteria: small $(0.10-0.29)$; medium $(0.30-0.49)$; and large $(\geq 0.50)$ 
Table 4 Case study profiles

\begin{tabular}{|c|c|c|c|c|c|}
\hline Case & $\begin{array}{l}\text { No. of } \\
\text { employees }\end{array}$ & Area of expertise & Scope & Interview participants (duration) & Interview location \\
\hline Firm A & $\sim 360$ & $\begin{array}{l}\text { Civil and structural engineering, } \\
\text { infrastructure planning, value } \\
\text { engineering }\end{array}$ & $\begin{array}{l}\text { International } \\
\text { (8 offices: } 6 \text { in } \\
\text { Australia; } 2 \\
\text { overseas ) }\end{array}$ & $\begin{array}{l}\text { - } 1 \text { senior structural engineer (45 mins) } \\
\text { - } 2 \text { junior structural engineers (60 and } 40 \text { mins) } \\
\text { - } 1 \text { structural drafting manager (20 mins) }\end{array}$ & Gold Coast office \\
\hline Firm B & $\sim 100$ & $\begin{array}{l}\text { Civil and structural engineering, } \\
\text { surveyors, geosciences }\end{array}$ & $\begin{array}{l}\text { Regional } \\
\text { (3 offices, all in } \\
\text { Queensland) }\end{array}$ & $\begin{array}{l}\text { - } 1 \text { engineering manager (50 mins) } \\
\text { - } 1 \text { senior structural engineer (40 mins) } \\
\text { - } 1 \text { junior structural draftsperson (40 mins) } \\
\text { - } 1 \text { senior structural draftsperson (45 mins) }\end{array}$ & Brisbane office \\
\hline Firm C & $\sim 250$ & $\begin{array}{l}\text { Architectural and interior design, } \\
\text { urban design and planning }\end{array}$ & $\begin{array}{l}\text { National } \\
\text { (4 offices in four } \\
\text { states) }\end{array}$ & $\begin{array}{l}\text { - } 1 \text { principal architect ( } 30 \text { mins }) \\
\text { - } 1 \text { senior architect (45 mins) } \\
\text { - } 2 \text { junior architects (45 and } 20 \text { mins) }\end{array}$ & Brisbane office \\
\hline Firm D & $\sim 100$ & $\begin{array}{l}\text { Architectural design and planning, } \\
\text { building refurbishment, interior } \\
\text { design, facilities planning }\end{array}$ & $\begin{array}{l}\text { International } \\
\text { (5 offices: } 3 \text { in } \\
\text { Australia; } 2 \\
\text { overseas) }\end{array}$ & $\begin{array}{l}\text { - } 1 \text { design associate }(30 \text { mins }) \\
\text { - } 1 \text { senior architect (50 mins) } \\
\text { - } \quad 2 \text { junior architectural technicians (30 mins each) }\end{array}$ & Brisbane office \\
\hline Firm E & $\sim 210$ & $\begin{array}{l}\text { Architecture, interior architecture, } \\
\text { urban design and planning }\end{array}$ & $\begin{array}{l}\text { International } \\
\text { (5 offices: } 3 \text { in } \\
\text { Australia; } 2 \\
\text { overseas) }\end{array}$ & $\begin{array}{l}\text { - } 1 \text { design director }(40 \mathrm{mins}) \\
\text { - } 1 \text { junior architect }(35 \mathrm{mins}) \\
\text { - } 1 \text { senior interior designer }(20 \mathrm{mins})\end{array}$ & Brisbane office \\
\hline
\end{tabular}


Table 5 Extract from the qualitative findings and rating results: Firm A - TCI construct

\begin{tabular}{|c|c|c|}
\hline Factors & Descriptive summary & Rating \\
\hline Vision & $\begin{array}{l}\text { Goals are often explained clearly by the supervisors to team } \\
\text { members in terms of what must be achieved and why. Team } \\
\text { members always need to follow the goals since they are usually a } \\
\text { part of the client's requirements. Since the firm always tries to } \\
\text { negotiate a reasonable project duration with clients, team goals are } \\
\text { usually realistic. }\end{array}$ & High \\
\hline Participative safety & $\begin{array}{l}\text { The team was described as close and tight where members know and } \\
\text { understand each other very well. Team members feel free to express } \\
\text { their ideas. They often exchange information, which mostly happens } \\
\text { informally. }\end{array}$ & High \\
\hline Task orientation & $\begin{array}{l}\text { Team members always work together to achieve the best possible } \\
\text { outcomes. However, although realising their own weaknesses, they } \\
\text { do not usually talk about and/or evaluate such weaknesses. }\end{array}$ & Medium \\
\hline $\begin{array}{l}\text { Support for } \\
\text { innovation }\end{array}$ & $\begin{array}{l}\text { Team members do not usually rush to a solution. They always spend } \\
\text { time discussing different approaches and techniques in order to find } \\
\text { better ways to solve problems. Team members appeared to be very } \\
\text { supportive in helping with the development of new ideas. }\end{array}$ & High \\
\hline & Firm A: Overall rating for TCI construct & High \\
\hline
\end{tabular}


Table 6 Within-case analysis results

\begin{tabular}{|c|c|c|c|c|c|}
\hline \multirow{2}{*}{ Construct/Factors } & \multicolumn{5}{|c|}{ Case rating } \\
\hline & Firm A & Firm B & Firm C & Firm D & Firm E \\
\hline \multirow{4}{*}{$\begin{array}{l}\text { Leadership for Innovation (LFI) } \\
\text { - } \quad \text { Innovation championing } \\
\text { - } \quad \text { Creativity stimulation and inspiration } \\
\text { - } \quad \text { Engagement and support }\end{array}$} & High & High & Medium & High & High \\
\hline & High & High & Medium & Medium & High \\
\hline & High & Medium & Medium & High & High \\
\hline & High & High & High & High & High \\
\hline \multirow{5}{*}{$\begin{array}{l}\text { Team Climate for Innovation (TCI) } \\
\text { - } \quad \text { Vision } \\
\text { - } \quad \text { Participative safety } \\
\text { - } \quad \text { Task orientation } \\
\text { - } \quad \text { Support for innovation }\end{array}$} & High & High & High & Medium & High \\
\hline & High & High & High & High & High \\
\hline & High & High & High & Medium & High \\
\hline & Medium & Medium & High & Low & High \\
\hline & High & High & Medium & Medium & High \\
\hline \multirow{4}{*}{$\begin{array}{l}\text { Organisational Culture for Innovation (OCI) } \\
\text { - } \quad \text { Propensity for creativity } \\
\text { - } \quad \text { Freedom and autonomy } \\
\text { - } \quad \text { Innovation support and facilitation }\end{array}$} & High & Medium & High & Medium & High \\
\hline & High & Medium & Medium & Medium & High \\
\hline & High & High & High & High & High \\
\hline & High & Medium & High & Medium & High \\
\hline \multirow{4}{*}{$\begin{array}{l}\text { Innovation Diffusion Outcomes (IDO) } \\
\text { - Innovative design products } \\
\text { - Innovative design practices } \\
\text { - } \quad \text { Advanced technology utilisation }\end{array}$} & High & Medium & High & Medium & High \\
\hline & High & Low & High & Medium & High \\
\hline & High & Medium & High & High & High \\
\hline & Medium & Medium & Medium & Medium & High \\
\hline \multirow{3}{*}{$\begin{array}{l}\text { Business Performance (BPM) } \\
\text { - } \quad \text { Economic growth } \\
\text { - } \quad \text { Client satisfaction }\end{array}$} & High & Medium & High & Medium & High \\
\hline & High & Medium & High & Medium & High \\
\hline & High & Medium & High & Medium & High \\
\hline
\end{tabular}


Table 7 Cross-case analysis results

\begin{tabular}{|c|c|c|c|c|c|c|}
\hline \multirow{2}{*}{ Case } & \multicolumn{5}{|c|}{ Construct rating } & \multirow{2}{*}{ Pattern matching result } \\
\hline & LFI & TCI & OCI & IDO & BPM & \\
\hline Firm A & High & High & High & High & High & $\begin{array}{c}\text { Perfect match to } \\
\text { Predicted Pattern } 1\end{array}$ \\
\hline Firm E & High & High & High & High & High & $\begin{array}{c}\text { Perfect match to } \\
\text { Predicted Pattern } 1\end{array}$ \\
\hline Firm C & Medium & High & High & High & High & $\begin{array}{c}\text { Good match to } \\
\text { Predicted Pattern } 1\end{array}$ \\
\hline Firm D & High & Medium & Medium & Medium & Medium & $\begin{array}{c}\text { Good match to } \\
\text { Predicted Pattern } 2\end{array}$ \\
\hline Firm B & High & High & Medium & Medium & Medium & $\begin{array}{c}\text { Partial match to } \\
\text { Predicted Pattern } 2\end{array}$ \\
\hline
\end{tabular}

